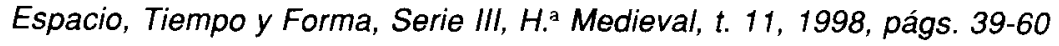

\title{
Menores y huérfanos en la comunidad castellana de Brujas. Una primera aproximación a su estudio
}

\author{
Betsabé Caunedo del Potro y Margarita Sánchez Martín*
}

\begin{abstract}
RESUMEN
Los mercaderes castellanos que negociaban en Europa buscaron formas de asociación que, además de favorecer sus intereses profesionales,

cumpliesen una tarea asistencial, proporcionando a sus miembros ayuda $y$ apoyo. Es en una de esas funciones

en la que vamos a fijar nuestra atención en el presente trabajo, en la protección que la Nación española de

Brujas ofrecía a sus miembros más desvalidos: viudas y huérfanos de mercaderes allí residentes.

Contemplamos los períodos de minoria de edad como especialmente delicados en la historia de las familias de mercaderes, pues podemos decir que suponian el principio del fin, al menos en lo que se refiere a su vinculación con el mundo de los negocios. La obsesión por conservar sus bienes suponía no incrementarlos.

La ya disgregada hacienda paterna, que habia sufrido diversas particiones,
\end{abstract}

\section{ABSTRACT}

The Castilian merchants who traded in Europe looked for forms of association which, apart from fulfilling a helping task, also favoured their professional interests, providing their members with help and support. It is in one of these functions that we are going to look at in this work, focusing our attention on the protection which the Spanish Nación in Bruges offered its more helpless members: widows and orphans of the merchants who were resident there.

We will look at the periods of age of minority especially sensitive in the history of the merchants families, we could say which were the beginning of the end, and least in what was referred to as their links with the trading world. The obsession for conserving their goods meant non increasing them. The already disintegrated paternal propery that had suffered various divisions could

* Universidad Autónoma de Madrid. 
no podia soportar ni resistir la inactividd de la inversión durante una larga espera. not withstand or endure the inactivity in investment during a long period of time.

La existencia de colonias de mercaderes castellanos ubicadas en diferentes puntos del Occidente medieval ha suscitado, en los últimos años, un renovado y creciente interés entre los historiadores. De conformarnos con lacónicas menciones acerca de su existencia, fundación, privilegios... hemos pasado a profundizar en aspectos sobre su funcionamiento, estructura organizativa, competencias... y a contemplarlas como marcos de solidaridad entre sus miembros 1.

De todas estas Naciones, la primera, más importante y mejor conocida es la de Brujas que, si bien agrupaba a diferentes mercaderes del interior peninsular, acabaría monopolizada y controlada por sus miembros burgaleses, en tanto en cuanto éstos se constituyeron en árbitros del comercio exterior casteliano en la Ruta del Cantábrico a fines de la Edad Media, aunque no en sus únicos beneficiarios ${ }^{2}$.

De todos los aspectos que pueden converger en el estudio de las colonias de mercaderes castellanos en Occidente, y más en concreto, de la llamada Nación, queremos destacar un aspecto inserto, sin duda, en la capacidad de los mercaderes castellanos de establecer unas formas de integración asociativa que los unían, protegían y hacian fuertes para sobreponerse a la disgregación social que su propia condición de extranjeros impulsaba. Unidos en defensa de unos intereses profesionales, no olvidaron tampoco unas funciones asistenciales como la ayuda y protección de aquellos a quienes podemos considerar más desvalidos - aunque no totalmente faltos de recursos al tratarse de un grupo socialmente privilegia-

\footnotetext{
Mención especial merece el trabajo de H. CASADO ALONSO, "Las Colonias de mercaderes castellanos en Europa (s. $x V-x v 1)$ ), que se inserta en otro más amplio en el que el mismo historiador figura como editor, Castilla y Europa. Comercio y Mercaderes en los siglos XIV, xV y xVl, Burgos, 1995, compuesto por nueve estudios en torno al tema. A ellos remitimos y también a la biblicgrafía que citan. Sobre el influyente y nutrido grupo de los burgaleses véase M. SÁNCHEZ MARTiN, «Mercaderes burgaleses en Flandes. Actividad económica y vida privada, según el Antiguo Cartulario del Consulado de España en Brujas (Primera Parte, de 1280 a 1550)" en La Península Ibérica en la Era de los Descubrimientos, 1391-1492. Actas de las III Jornadas Hispano-Portuguesas de Historia Medieval, Sevilla, 1997, 453-468.

2 La activa presencia de burgaleses en esta ruta ha sido resaltada con ocasión de la conmemoración del $\vee$ Centenario del Consulado de Burgos. Destacamos especialmente los trabajos incluidos en las Actas del $V$ Centenario del Consulado de Burgos, Burgos, 1995. También B. Caunedo del Potro, Mercaderes Castellanos en el Golfo de Vizcaya, Madrid, 1983, se ocupa del dinamismo mercantil burgalés.
} 
do-: las viudas y huérfanos de mercaderes castellanos residentes en el extranjero. Es en éstos en quienes vamos a centrar nuestra atención en el presente trabajo, conscientes de que omitimos otras tareas asistenciales, así como las benéficas, piadosas, y por supuesto, las profesionales.

\section{EL LIBRO DE TUTORÍAS DE LA NACIÓN}

Por su indefensión, viudas y huérfanos entran dentro de la categoría de "pobres" en sentido amplio ("desventurados", "desgraciados") a los que la Iglesia y la sociedad debían proteger y auxiliar. En el caso de los mercaderes castellanos de Brujas esta prescripción moral se tradujo desde el punto de vista institucional en la atribución a los Cónsules de la Nación, de la condición de tutores supremos de los pequeños menores allí residentes. A tal fin, en ayuntamiento general del 2 de octubre de 1535 se acuerda la elaboración de un registro de tutelas en el que

“... se asentasen las cosas que tocasen a los menores uerfanos que quedasen de los defuntos de nuestra naçion y de los depositos y otras cosas, las quales asta aqui no se ponian tan enteramente por nota, para que despues a cada uno que viniese se le pudiese dar claridad dello..." ${ }^{3}$.

Así, a partir del año 1536 toda decisión o documento directa o indirectamente relacionado con los huérfanos de la Nación y con la gestión de sus bienes será cuidadosamente anotado en el "Libro de Tutorías y otras cosas que tocan a los menores", actualmente custodiado en el Archivo Municipal de Brujas ${ }^{4}$. Además del nombramiento de tutores y curadores, el Libro de Tutorías recoge testamentos, estados de cuentas y balances, licencias de venta de inmuebles y de inversión en rentas, depósitos, reconocimiento de deudas, solicitudes de emancipación, ...

Del propio análisis interno del Libro podemos hacer ya unas primeras observaciones acerca del importante grado de integración alcanzado por nuestros mercaderes en esta plaza europea. En primer lugar, se utilizan indistintamente las lenguas castellana y francesa. Es más, el castellano

\footnotetext{
3 J. MARÉCHAL, Europese aanwezigheid te Brugge, Brugge, 1985, 247.

4 Forma parte de los fondos del Archivo del Consulado de España (Spaanse Consulaat) conservado en el Archivo de la ciudad de Brujas. Se trata de un volumen de $410 / 280 \mathrm{~mm}$. encuader nado en cuero oscuro y labrado con las armas de Burgos, Cabeza de Castilla. Consta de 94 páginas foliadas (en números romanos hasta la página 45 y en números árabes desde la 46 hasta el final) además de un gran número de hojas sueltas entre las páginas y de cuadernillos cosidos al mismo libro. Cronológicamente abarca de 1536 a 1577.
} 
que hablan los miembros de la Nación está tan fuertemente contaminado de galicismos que difícilmente podemos penetrar en todo su sentido sin tener algunas nociones de la lengua gala. Apenas encontramos un solo folio del registro sin que aparezcan términos en francés utilizados como tales o castellanizados; simplemente a título de ejemplo señalaremos que, en el Libro, los de la Nación reciben el nombre genérico de "supuestos", del francés suppôt (súbdito), los huérfanos son llamados "orfelines", del francés orphelin, los fiadores o garantes ante la ley aparecen como "plesges», del francés plège, ... Por último, la elaboración de un simple elenco onomástico de los hijos de los mercaderes de la Nación proporciona un índice más de su integración en la sociedad de acogida: abundan nombres típica e inequívocamente flamencos como Barbara, Josyne, Catherine, Cristopher, Jacques, etc.

Dejando a un lado estos aspectos y pasando al propio contenido del Libro, señalaremos que a los cónsules como "a supremos tutores de los huerfanos y pupilos hijos de los supuestos desta naçion de España", se dirigen repetidamente todos los mercaderes castellanos cuando se rompe, por el fallecimiento de alguno de los progenitores, esa primera y fundamental unidad de sociabilidad que constituye la familia. Es, sin duda, este el momento en que de forma más patente se manifiesta lo indispensable de esa solidaridad corporativa. Es el caso, por ejemplo, de los hijos y herederos del difunto Pedro de Porres cuando también pierden a su madre Juana del Castillo. Si la falta de su padre ya les habia hecho acreedores de una merecida solidaridad, la más tardía de su madre, los sumía en el más descarnado desamparo, presentándose como más necesitados de ayuda, afecto y protección ${ }^{5}$.

En este trabajo sobre los menores, huérfanos castellanos en Brujas, vamos a utilizar la magnífica fuente mencionada, el Libro de Tutorias... pero sólo como anticipo, breve presentación, de un trabajo más amplio y

5 En 1559 los menores citados se dirigen a los Cónsules de la Nación manifestando su desamparo en los siguientes términos: «Muy magnificos señores, suplican umilmente a vuestras mercedes Juan de Porres y Leonor de Porres en su nombre y en nombre de sus hermanos Pedro y Martin y Bernardino y Antonio y Maria y Clara de Porres, todos hijos legitimos del señor Pedro de Porres y la señora Juana del Castillo, a quien Nuestro Señor tenga en su gloria, como de pocos dias aca a plazido a Nuestro Señor llebar a su gloria a la dicha señora su madre Juana del Castillo y despues de su fallecimiento que fue a onze de mayo pasado no a abido persona que se aya encargado de la tutela de los dichos suplicantes ni de sus hermanos, ni quien tome el govierno y de la orden que cumple en la casa mortuoria de la dicha señora su madre y a la causa a estos suplicantes y a sus hermanos y ermanas por ser huerfanos y menores se les recreçe gran daño, y por eso acuden a vuestras mercedes como a supremos tutores delos huerfanos y pupilos deios supuestos desta naçion de España”. Se trata de una hoja de papel doblada sin foliar, que se encuentra en el lote de Papeles sueltos del Libro de Tutorías. 
pormenorizado, que pretende cubrir al lado de aspectos tan concretos como la figura del tutor, curador, su persona, función, responsabilidades... otros más generales como el mostrar el desarraigo del menor que ha sufrido, con la pérdida de su progenitor, una brusca salida de la infancia, y ha visto cómo se aceleraba su marcha hacia un mundo adulto, difícil y competitivo, en ocasiones hostil. Las frías consideraciones de las que son objeto, los meticulosos cálculos a los que se ven sometidos, nos darán buena muestra de su necesidad de enfrentarse a un ambiente adverso en el que no son más que piezas descolocadas en un lujoso tablero, siempre fáciles de mover. En esa situación, comprueban con más crudeza, su dependencia absoluta de los demás para satisfacer sus necesidades vitales.

Ahora, como una primera y muy breve presentación de tan apasionante tema, vamos a fijarnos en algunos de los aspectos anunciados.

\section{NUPCIALIDAD Y NATALIDAD}

En los años recogidos por el Libro de Tutorías ${ }^{6}$ necesitan el amparo y protección consular, al menos, los hijos habidos en 40 matrimonios, los de:

- Francisco de Jerez -

- García de Castro - Antohine Puils (1)

$$
\text { - Josina de Aresti (2) }
$$

- Gregorio Pesquer - Isabel de Salinas

- Francisco de Aranda - Guertende de Berenique

- Francisco de la Torre - Ana Jaquelot

- Diego de San Vítores.

- Nossio Pardo - Connelie Vander Rique

- Bernardino del Castillo - Clara de Aresti

6 El Libro de Tutorias recoge, como hemos dicho, el periodo transcurrido entre 1536 y 1577 , sobrepasando ampliamente el período medieval. No obstante este hándicap cronológico, nos atrevemos a trasladar sus prácticas a los últimos años de la Edad Media puesto que ellos mismos aluden a cómo lo venian realizando "desde mucho tiempo aca", además de las menciones acerca de este mismo tema que, para el siglo Xv, aparecen en el Cartulaire de l'Ancien Consulat d'Espagne à Bruges, Bruges, 1901-1902, de L. GILLIODTS VAN SEVEREN. Realmente no creemos que se hubiesen producido cambios sustanciales en el nombramiento de tutores para estos menores ni en la gestión de su patrimonio. Con carácter general remitimos al completo trabajo de A. MERCHÁN ÁLVAREZ, La tutela de los menores en Castilla hasta finales del siglo xv, Sevilla, 1976, que contínuamente hemos de tener presente. 
- Silvestre Pardo - Josyne López Pardo

- Gonzalo de Aguilera - Ana de Castro

- Juan de Montenegro - Guertende de Berenique

- Juan de Salinas - Isabel de Quintanadueñas

- Pedro de Valencia - Clara de San Vítores (1)

- Isabel de Quintanadueñas (2)

- Antonio de Villafranca - Godeliba Vandebelde

- Francisco Fernández de Villegas - Adriana de Boot

- Juan de Villalpando -

- Diego de Avila - Magadalena de Mill

- Nicolás de Valdaura - Ana Poorters

- Lope de la Corona - Francisca de Pamole

- Diego de Astudillo - María de Cisneros

- Francisco García de Almaraz - María de Carrión

- Lorenzo de Espinosa - Jehanne Castellynes

- Luis Gallo - Catalina Van Viuen

- Alonso Páez - Juana de la Torre

- Juan de Camargo - Bárbara de Baerse

- Alvaro de Castro - María Campo

- Juan de Medina - Josina de Carrión

- Fernando de Matute - Josina Crampe

- Antonio de Nájera - Josyne de Beyt

- Francisco de la Maza - Bárbara de Camargo

- Silvestre Pardo - Adriana Pesquer

- Juan de la Peña - María Yáñez

- Diego Pardo - Isabel de Villegas

- Juan de Matanza - Bárbara Pardo

- Silvestre de la Torre - Angela de Granada

- Luis de la Vega - Francisca de Castro

- Pedro de Porres - Juana del Castillo

- Diego de Tordomar - Clara Yáñez 
En este pequeño grupo, el $39 \%$ de los castellanos, habían contraído matrimonio con una mujer flamenca, dato que apoya, una vez más, la facilidad de integración de los castellanos en Brujas por via matrimonial ${ }^{7}$. Se trata de García de Castro, Francisco de Aranda, Francisco de la Torre, Nossio Pardo, Juan Montenegro, Antonio de Villafranca, Fancisco Fernández de Villegas, Diego de Avila, Nicolás de Valdaura, Lorenzo de Espinosa, Luis Gallo, Juan de Camargo, Fernando de Matute, Antonio de Nájera y Juan de Montenegro. Éste último y Francisco de Aranda tuvieron, incluso, la misma esposa flamenca: Gertrude de Varnicque ${ }^{8}$, 10 que no nos resulta extraño, moviéndose como se movían en un mismo círculo restringido. Esta mujer, viuda de Francisco de Aranda y con cuatro hijos menores ${ }^{9}$, contraerá un nuevo matrimonio con Juan Montenegro. Con él acabará trasladándose a la Península y residiendo en Logroño. Desde esta localidad aparece años más tarde como heredera de uno de sus hijos, Bernardino de Aranda, fallecido en Fiandes ${ }^{10}$. Tras haber solucionado diferencias con sus otros hijos: Francisco y Diego de Aranda, todos ellos habidos en su primer matrimonio, recibirá la cantidad de 128 libras y 4 sueldos, moneda de Flandes, que hasta ese momento custodiaba la Nación ". Si hablábamos de la integración de los castellanos en el ex-

7W.D. PHILLIPS, "Local integration and long-distance ties: the Castilian-Community in Sixteenth Century Bruges", Sixteenth Century Journal, XVII, 1 (1986), 33-49 habia sido uno de los primeros especialistas en insistir en esta vía de integración en la ciudad de Brujas al analizar 39 testamentos del siglo xvi. Un tercio de sus redactores estaba casado con una flamenca. $H$. CASADO, "Las Colonias de Mercaderes..." amplía este dato con 20 casos más, y los compara, además con el comportamiento en otras ciudades mercantiles, 38-40.

8 Aparece con este nombre y con el de Guertende de Berenique, pero no dudamos de que se trata de la misma persona.

9 En 1535 y 1536 se presentan ante los Cónsules de la Nación cuentas y gastos de los cuatro hijos de Francisco de Aranda. Tras las mismas Juan de Montenegro declarará, "nos, Juan de Montenegro, como marido de la madre de los menores, hijos de Francisco de Aranda, e yo Fernando de Valladolid, como pariente mas propinco de los menores suso dichos, deçimos que esta cuenta ha dado Diego de Santo Domingo, que es de los bienes que ha reçibido de los dichos menores», fol. II. Continúan las cuentas en el fol. VIII.

10 En 1555 Diego de Montenegro se presenta ante los Cónsules de la Nación con un poder de su hermano Juan, vecino de Logroño, y de su esposa Gertruic de Varnicque. "Yo, Diego de Montenegro, español residente en esta villa de Brujas del condado de Flandes, por y en nombre y como procurador de Juan de Montenegro, mi hermano, y de la señora Gentruicq Van Vernuicq, su muger, vezinos de la çiudad de Logroño en Castilla, en vertud del poder que dellos tengo". En el poder se especifica: "para que por nosotros y en nuestro nombre e para nos mismos podais pedir y demandar, reçebir y cobrar qualesquier maravedis y otras cosas que a mi la dicha Gertruicq de Vernuicq me perteneçe e puedan perteneçer de los bienes y herençia de Bartolome de Aranda, $m i$ hijo, y de Francisco de Aranda, mi primer marido, que al presente el dicho Bartolome de Aranda, mi hijo, es muerto e falleçido desta presente vida en el dicho condado de Flandes". El poder se concedió en Logroño, a 13 de noviembre de 1550, y se inserta en el Libro, fol. XLII .

1 Ese dinero lo custodiaba la Nación "de los bienes que perteneçen a Bartolome de Aranda, defunto, hijo de Francisco de Aranda, defunto, y de la dicha Gertruicq Van Vernuicq, su primera 
tranjero por vía matrimonial, en este caso, la integración también se efectuaría a la inversa. Sería ella la que, abandonando su país natal, tuviese que adaptarse a una nueva y diferente realidad.

Estos matrimonios generaron un total de 129 hijos,

\section{PAREJAS}

№ DE HIJOS

Francisco de Jerez

García de Castro - Anthoine Puils

- Josine de Aresti (2) 3

Gregorio de Pesquer - Isabel de Salinas 2

Francisco de Aranda - Guertendre de Berenique 4

Francisco de la Torre - Ana Jaquelot 7

Diego de San Vítores - 3

Nosio Pardo - Connelie Vander Rique 2

Bernardino del Castillo - Clara de Aresti 2

Silvestre Pardo - Josyne López Pardo $\quad 7$

Gonzalo de Aguilera - Ana de Castro 2

Juan de Montenegro - Guertendre de Berenique 2

Juan de Salinas - Isabel de Quintanadueñas 2

Pedro de Valencia - Clara de San Vitores (1) 1

- Isabel de Quintanadueñas (2) 7

Antonio de Villafraca - Godeliva Vandevelde 4

Francisco Fdez. de Villegas - Adriana de Boot 2

Juan de Villalpando - $\quad 3$

Diego de Avila - Magdalena de Mill 5

Nicolás de Valdaura - Ana Poorters 1

Lope de la Corona - Francisca de Pamole 2

Diego de Astudillo - María de Cisneros $\quad 4^{12}$

Francisco García de Almaraz - María de Carrión 1

Lorenzo de Espinosa - Jehanne Castellynes $\quad 7$

muger, $y$ al presente muger del dicho Juan de Montenegro, sobre que Francisco de Aranda e Diego de Aranda, hermanos legitimos del dicho Bartolome de Aranda, defunto, ventilaron pleyto contra la dicha Gertruicq Van Vernuicq, su madre, y contra mi el dicho Diego de Montenegro en su nombre, pretendiendo ser herederos del dicho defunto Bartolome de Aranda. Los quales Francisco e Diego de Aranda declararon por ante nos los dichos consules a los seys dias del mes de julio ultimo pasado como en sus libres voluntades por tener amor e paz con los dichos Juan Montenegro, su padrasto e Gertuicq Van Vernuicq, su madre, se desistian e apartaban del dicho pleito y renunçiaban tal action y derecho que pretendian aver o tener de los dichos bienes del dicho defunto", fol. XLII.

12 Diego de Astudillo aporta al matrimonio un hijo natural al que impone su mismo nombre. 
Luís Gallo - Catalina van Viuen

Alonso Páez - Juana de la Torre

Juan de Camargo - Bárbara de Baerse 4

Alvaro de Castro - María Campo 3

Fernando de Matute - Josina Crampe 5

Antonio de Nájera - Josyne de Beyt $\quad 7$

Francisco de la Maza - Bárbara de Camargo 1

Silvestre Pardo - Adriana Pesquer 3

Juan de la Peña - María Yáñez 1

Diego Pardo - Isabel de Villegas 9

Juan de Matanza - Bárbara Pardo 3

Luís de la Vega - Francisca de Castro 3

Silvestre de la Torre - Ángela de Granada 1

Diego de Tordomar - Clara Yáñez

lo que nos arroja una media de 3,05 hijos por pareja, cifra que encierra situaciones que oscilan desde el hijo único hasta las familias numerosas de 8 ó 9 vástagos. Por supuesto carecemos de datos suficientes ni siquiera para aproximarnos a lo que podríamos denominar índice de fecundidad, pero si podemos acercarnos, de un modo puntual y concreto, a lo que pudo haber sido éste en el seno de la comunidad de mercaderes castellanos asentados en Brujas, conscientes de que los datos que presentamos son totalmente insuficientes, parciales e incompletos. La principal carencia es que, en general, no aparece en estos registros referencia alguna a los hijos ya emancipados o a los fallecidos antes de la muerte de su(s) progenitor(es). De ahí que la cifra de 129 hijos haya de ser leída como "número mínimo de hijos".

En principio, tendíamos a adjudicar a esta comunidad un elevado número de hijos por pareja, una tasa alta, y sin embargo, nos encontramos con que ésta fue relativamente baja. $Y$ pensábamos en una fecundidad alta porque, no olvidemos, nos encontramos ante la Nación Castellana en Brujas. Se trata de mercaderes en un país extraño, extranjeros, que aunque acapararon prestigio y poder $y$ aparecen rodeados de todo tipo de privilegios... no podian dejar de ser y sentirse diferentes. En una sociedad en la que las relaciones interpersonales estaban dominadas por el individualismo, la competencia en torno a la riqueza y la posición social, cuyas calles podian rebosar de vecinos "distintos", desconcertantes, de quienes casi no nos podriamos fiar, que nos miran con envidia o desprecio, a quienes apenas entendemos cuando nos dan los buenos días, y en la que los parientes se hallan lejos, en Burgos, el deseo de afecto se dejaría sentir con más fuerza. Ante este aislamiento, los miembros de la propia Nación, los «amigos» o al menos compañeros, darían 
la solidaridad que todos necesitaban, y los niños, sus hijos, ayudarían a prodigar el cariño y afecto que también todos anhelarían. Por eso pensamos, en principio, que los mercaderes burgaleses en Brujas, responderían con una alta tasa de fecundidad al relativo aislamiento que, al menos temporalmente, sufrían. $\mathrm{Y}$ sin embargo, nos encontramos con una tasa relativamente baja, apenas algo más de 3 hijos por pareja ${ }^{13}$.

Este número inmediatamente debemos elevarlo, aunque no sabemos hasta qué punto. Pero debe ser tomado, a nuestro juicio, como índice mínimo a tenor de la fuente consultada. Si se trata del Libro de Tutorías hemos de pensar en enlaces poco fecundos, por lo menos enlaces de "corta duración", al verse truncados por el fallecimiento prematuro de uno de sus miembros. Suponemos enlaces de "corta duración" dada la necesidad de procurar tutores a los menores, aunque en realidad sólo en el caso de la unión de Pedro de Valencia y Clara de San Vítores sabemos con certeza que el matrimonio duró menos de dos años ${ }^{14}$. En otras ocasiones podemos suponer la ruptura del vínculo conyugal en edad de procrear con alusiones a hijos póstumos. Así Antonio de Villafranca nos habla, en el momento de nombrar tutores, de sus tres hijos nacidos y del embarazo de su mujer, Godeliba Van de Velde ${ }^{15}$. Luis Gallo fallecía también antes del nacimiento de su segundo hijo, Luis ${ }^{16}$. Y Pedro Porres dejaría siete pequeños, y a su esposa Juana del Castillo, pendiente del nacimiento del que sería su octavo hijo ${ }^{17}$. Al lado de estos casos, solamente Fernando, hijo de Juan de Matanza y de Bárbara Pardo, era mayor de edad en el momento de producirse el fallecimiento de su padre, precisando tutores sus hermanos menores, Juan y Catalina. Será, además, él

13 Lejos de la tasa de natalidad de 5,1 hijos por pareja calculada por W. D. Phillips tras el análisis de los testamentos redactados en Brujas ante el notario Pedro de Paredes entre 1544 y 1569.

14 Habian contraído matrimonio en 1539 y en 1542 ella ya había fallecido. En este corto intervalo sólo tuvieron una hija, Leonor de Valencia. "Declaraçion que hace Pedro de Valençia de los bienes que ay perteneçientes a el e a su hija presentada a dos de deziembre de 1543", fol. XII.

15 El 29 de enero de 1545, Alonso de Santa Gadea, Juan de Camargo y Juan del Castillo, declararon cómo Antonio de Villafranca, "defunto, les avia nonbrado por tutores e curadores de sus tres criaturas bibas e mas que la que esta por nazer", fol. XV

16 Una claúsula del testamento del mercader difunto nos dirá "e cumplido este mi testamento en el remanente de mis bienes dexo e nombro por mis universales herederos a Ana Gallo, mi legitima hija y de la señora Catalina Van Billen, mi muger, y al fruto que Dios nos diere abiendo recibido agua de Espiritu Santo, por quanto declaro que la dicha señora Catalina Van Villen queda preñada”, fol. 34.

17 Pedro de Porres también anuncia en su testamento el embarazo de su esposa "dexo e ynstituyo por mis legitimos herederos universales a Juan y Pedro y Martin y Bernardino e Antonio de Porres e a Leonor e Maria de Porres, mis hijos y hijas de la dicha mi muger// y declaro que la dicha Juana del Castillo, my muger, queda preñada", Libro de Tutorías. Papeles Sueltos. Cuadernillo de una hoja de papel doblada, sin foliar. 
mismo quien asuma la tutoría efectiva, cumpliendo, de este modo, las disposiciones testamentarias paternas ${ }^{18}$. En otras dos ocasiones, el mercader moribundo prevee el matrimonio inminente de alguna de sus hijas, por lo que las suponemos ya de edad para contraerlo. Así, Diego Pardo, cuando en su testamento nombra tutores para sus ocho hijos menores, designa como tal a su esposa Isabel de Villegas, quien perdería tal condición en caso de contraer segundas nupcias, y a su futuro yerno, Antonio de la Vega, "si se casare con la sobredicha mi hija Josina" ${ }^{19}$. Cuatro o cinco años después del fallecimiento de su padre, contraerá matrimonio Josina de Avila, hija de Diego de Avila y Madalena de Mill ${ }^{20}$.

Si comparamos este índice, 3 hijos por pareja con otros conocidos - familias nobles castellanas - nos encontramos con que se acerca a la tasa "normal» observada en los grupos privilegiados de la sociedad castellana de su tiempo ${ }^{21}$.

\section{TUTORES. NOMBRAMIENTO Y FUNCIONES}

El fallecimiento del cabeza de familia provocaba en sus hijos una brusca salida de la infancia. Se abría una etapa incierta iniciada con el nom-

18 Así se desprende de una claúsula de su testamento: "Ytem nombro por tutores de mis hijos Juan y Catalina de Matança a Fernando de Matança, mi hijo, y al señor Nicolas de Tordomar, dean de San Donaçio, y declaro que por quanto el dicho señor dean no es onbre de negoçios que el dicho Fernando de Matanza tenga y posea los bienes que a los dichos Juan y Catalina, mis hijos, perteneçen, hasta que los dichos Juan de Matança y Catalina de Matança, mis hijos, sean de hedad", fol. 61 .

19 Así lo dispone en una claúsula de su testamento, "Ytem nombro y declaro por iutores y curadores de personas y bienes de mis herederos naçidos y por naçer, a la señora Doña Ysabel de Billegas, mi esposa y muger, y al señor Juan Lopez Gallo, señor de Male y Çiçela, pero entiendese y declaro que si la dicha muger se tornase a casar que no quiero que sea tutora ni curadora, $y$ tambien declaro por tutor y curador al señor Antonio de la Vega si se casare con la sobredicha mi hija Josina y si no se casare no, a los quales pido por merçed lo acepten por serviçio de Dios y por me hazer merçed y que Dios les de buena mano derecha en todo"..., fol 61.

20 En febrero de 1547, se solicita ante los Cónsules un cambio de tutores para los hijos menores de Diego de Avila y Madalena de Mill, invocando el testamento paterno, fol. XXI, y en Febrero de 1551, los Cónsules tendrán que aprobar la entrega a Josina de Avila de 217 libras, 2 sueldos y 2 dineros de gruesos por parte de sus tutores ya que había contraído matrimonio, fol. XXXII.

21 Fijémonos, por ejemplo, en el número de tres hijos por pareja que ofrece R. SANCHEz SAUS como media para la nobleza jerezana, "Nuevas aportaciones al estudio de la nobleza jerezana", Actas de las /I Jornadas de Historia de Jerez, Jerez de la Frontera, 1990, 50 y que compara con el que él mismo ha ofrecido para la nobleza sevillana $(3,2)$, C. QuiNTANILLA para la cordobesa (que llegaría a 4), y G. GERBERT para la extremeña $(4,5)$.

Falay Hassan Abed AL-HUSSEIN aporta el dato de 5,27 hijos por pareja en el grupo de mercaderer medinenses a mediados del siglo XVI (1528-1580), en "Estrategia de los mercaderes en matrimonio y herencia", Historia de Medina del Campo y su tierra, II, Valladolid, 1986, 183. 
bramiento de tutores, quienes debían proteger y asistir a los menores, administrar su patrimonio, proporcionarles el amparo, la protección y salvaguarda que iban a necesitar y, por supuesto, representarles en todos los actos civiles.

Normalmente los tutores son designados en el testamento - tutela testamentaria $-{ }^{22}$, y vemos que la condición recae en primer lugar en el cónyuge superviviente y en aquellas otras personas, parientes, amigos o socios que, residiendo en Brujas, mantenían una especial relación con el fallecido. Una regla generalmente observada es la que hace del hijo mayor tutor de sus hermanos más pequeños, norma que se mantiene también por lo que respecta a hermanos políticos, de modo que es frecuente que el cuñado represente a los hermanos menores de su esposa.

¿Qué cualidades se consideran idóneas para desempeñar la tutela?. Las Partidas hablan de personas "de buen seso", "de buena fama" y "que no cobdicen heredar lo suyo" ${ }^{23}$. En esta misma línea, el Libro de Tutorías insiste en el nombramiento de "personas habiles y sufiçientes". Requisitos que están lejos de ser un mero recurso retórico; asumir la gestión patrimonial de un mercader cuya fortuna estaba integrada tanto por bienes muebles como inmuebles, capital invertido en operaciones comerciales y financieras, ... exige del tutor un profundo conocimiento y familiaridad con los instrumentos de pago propios de la época, con los sistemas contables y con la tenencia de los libros de comercio. Es lo que en su propio lenguaje se expresa como "ser entendido en cuentas".

Una vez nombrados de acuerdo con los requisitos señalados, los tutores debían presentarse ante los Cónsules de la Nación, para entrar en posesión de su cargo. Lope de la Corona designó como tutores a su esposa, Francisca de Pamole, a Andrés Manrique, su sobrino, a Diego de Villegas, su yerno, y a sus primos Antonio de Burgos y Juan de Castro ${ }^{24}$. Juan de la Peña se inclinó también por su esposa María Yañez y por su hermano Garcia de la Peña ${ }^{25}$. Diego Pardo igualmente por su esposa Isabel de

22 Los diferentes sistemas de designación de tutor pueden seguirse en el trabajo, ya mencionado, de A. MERCHÁN ÁlVAREZ, "La tutela...", 75-113. Este autor también diferencia claramente los dos aspectos en que podía desdoblarse la tutoría: el aspecto personal o cuidado de la persona del huérfano, y el aspecto patrimonial o administración de sus bienes, ibidem, 117-138.

${ }_{23}$ Siempre según las Partidas, dichos tutores podian ser "uno o tres o cinco e non mas, porque si alguna vegada desacuerdo oviesse entre ellos, aquello en que la mayor parte se acordase fuese valedero" (Partida VI).

24 Fol. XXVIII.

25 Fol. 60. 
Villegas y por Juan López Gallo ${ }^{26}$. Pedro de Valencia asimismo nombró a su esposa Isabel de Quintanadueñas, a Juan de Medina y a sus socios Juan de Peralta y Cristóbal Pesquer ${ }^{27}$. Francisca de Castro fue designada por su esposo Luis de la Vega junto con su yerno Yñigo de Salas ${ }^{28}$, y Juana del Castillo también por su esposo Pedro de Porres junto a Antonio de Guzmán ${ }^{29}$.

En el caso de no producirse esta disposición testamentaria ${ }^{30}$, son los propios cónsules los encargados del nombramiento de tutores buscando aquellas personas que, por su relación con los tutelados y en beneficio de los mismos, considerasen más idóneas. Volvemos a encontrar al mismo tipo de personas: los parientes más próximos de los pequeños o los socios y amigos del fallecido. Aquí observamos una cierta tendencia que nos llama la atención. El mercader en su testamento solía exigir a su esposa la condición de viuda para ejercer la tutoría. Así lo hará Diego Pardo con su mujer, la castellana Isabel de Villegas ${ }^{31}$, o Diego de Avila con respecto a Madalena de Mill ${ }^{32}$. También Juan de la Peña, a pesar de que en la misma claúsula testamentaria, había concedido a su viuda María

26 Fol. 61. No sabemos củal es el parentesco que le une a Juan López Gallo, señor de Mâle y Ciçela, pues en el documento sólo se especifica esta condición. Vuelve a presentarse este caso en el fol. LXXI.

27 "Dexo por mis universales testamentarios y tutores y curadores de mis hijos a Ysabel de Quintanadueñas, mi muger, y al señor Juan de Medina y al señor Juan de Peralta, todos tres juntos". Habla después del matrimonio de su hija con Cristóbal Pesquer, y añadirá una segunda claúsula "para ampliar este mi testamento y abiendo efeto el dicho matrimonio dexo por mi testamentario e tutor de mis hijos al dicho Cristobal Pesquer e poseedor de mi hazienda en compañya de la dicha Ysabel de Quintanadueñas y dicho Juan de Peralta», fol. LXXII.

28 Fol. 79.

29 Cuadernillo de una hoja de papel doblada, sin foliar; en blanco $2 \mathrm{v}$.

30 En muchos casos aparecen los tutores ratificados por la autoridad consular y desconocemos si se había producido o no una disposición testamentaria. En otros casos sí se especifica; asi María de Cisneros relata que uplugo a Nuestro Señor de llebar desta presente vida al señor Diego de Astudillo, mi marido, que aya gloria, syn hazer testamento ni codeçillo alguno". Ella reclama el nombramiento de tutora de sus tres hijos, que evidentemente los cónsules conceden, de acuerdo con el criterio habitual, fol. XXX. También pudo ocurrir que el testamento no fuese más que una declaración de voluntad en presencia de testigos o un testamento ológrafo que precisa su poste rior validación. Asi Pedro de Valencia declarará «que por quanto al tienpo que la dicha mi muger Clara de San Vitores Dios la llevo no quiso hazer testamento por ante notario diziendo tenya ma. rido e hija a quien perteneçia su hazienda e hizo un testamento breve delante el probinçial de los agostinos y otro traile de la dicha orden, el qual la dicha mi muger, que Dios tenga en gloria, otorgo por su boca e firmo de su nombre delante de los dichos frailes y el dicho probinçial lo firmo por testigo, que por quanto los dichos frailes se podrian morir o avsentar y por alguna cavsa o razon o diferençia podria venir a ser nesçesario de probar el dicho testamento es bueno e verdadero segund que en el se contiene", fol. XII. Vid. también nota 22

31 Vid. supra, nota 18.

32 En su testamento "avia nombrado por tutores de los dichos sus hijos a la dicha Madalena de Mill, su muger, entre tanto que estubiese viuda", fol. XXI. 
Yañez y a su hermano García de la Peña, gran disponibilidad y libertad en la administración de sus bienes, y había encomendado vivamente a su hijo una total obediencia a su madre, a quien otorga además una cierta preeminencia sobre su propio hermano ${ }^{33}$.

Mientras que el mercader solía exigir a su viuda que permaneciese en ese estado ${ }^{34} e$ insiste en esa situación, otro cirterio solía ser el de los cónsules quienes designan, en diferentes ocasiones, a los segundos esposos de las viudas como tutores de los hijos de ésta. $Y$ así Juan Montenegro lo fue de los hijos de Francisco de Aranda, en calidad de "marido al presente de la madre de los dichos menores" ${ }^{35}$, la flamenca Guertende de Berenique. Pedro de Valencia como segundo esposo de Isabel de Quintanadueñas también deberá asumir la tutoría de los hijos de ésta y Juan de Salinas, cuando uno de los tutores nombrados en el testamento paterno, Juan de Quintanadueñas, tiene que abandonar Brujas y regresar a la Península ${ }^{36}$. Al producirse la sustitución, se explica que se acude a él porque no hay pariente paterno próximo en Brujas que pueda hacerse cargo de los pequeños. El aceptó la tutela pero puso, a su vez, algunas condiciones ${ }^{37}$.

33 "Nombro e ynstituyo por mi unico fijo y heredero de mi el dicho Juan de la Peña y de la dicha mi querida muger Maria Yañez a Juan de la Peña nuestro hijo, para que los aya y herede el solo, al qual hecho mi maldiçion si fuere desobediente a su madre y no la onrare y acatare pues los hijos buenos asy lo deven hazer e Dios lo manda e nombro por sus tutores al señor Garcia de la Peña, mi hermano, y a mi querida muger Maria Yañez, para que aquello que le quedare asta ser de edad competente lo traten y administren como quisieren e bien visto les fuere en qualquir trato e negoçio que bien les paresçiere, e ruego e pido al dicho señor mi hermano se aga a boluntad de la madre, e pasado el tiempo de la tutela del dicho Juan de la Peña, nuestro hijo, quiero y mando y es mi boluntad que asta que llegue su tiempo de hedad de beinte y çinco años o tomare estado que la dicha su madre sola sea su curadora de sus bienes y los trate y beneficie y negoçie como a ella le pareçiere e bien visto le fuere, y el dicho mi hijo no pueda demandar a los dichos tutores ni curadores mas de aquello que ellos dieren, dixeren y declararen por sus simples juramentos, bien entendido que si la dicha mi querida muger se casare la aparto y desapodero desta tutela $e$ curadoria e nombro solo al señor mi hermano Garcia de la Peña por tutor e curador del dicho mi hijo», fol. 60.

34 Vid. infra nota 39.

35 Entre 1537 y 1542 se produce un cambio de tutores. En 1542 se habla de "los tutores nuevos puestos despues de ser ydo Diego de Santo Domingo, que son los señores Juan de Montenegro e Fernando de Valladolid", fol. IX.

${ }_{36}$ Juan de Quintanadueñas explica que debe ser relevado de la tutoría ya que "me voy e retiro en España como suelen azer algunos otros de nuestra naçion que tienen padre e superiores a quien obedeçer por cuyo mandado me es fuerça de me retirar en España», fol. XIX.

37 "Porque en esta villa yo no se que aya parientes del estado paternal de los dichos menores", fol. XIX. "E luego el dicho Valençia dixo que el açeptaba la dicha tutela con tal condiçion que si de caso Dios fuere serbido de llebar a Ysabel de Quintanadueñas, su muger, madre de los dichos menores, antes que ellos sean de hedad competente para administrar sus bienes, que en tal caso, ayamos de elegir de nombrar y elegir otro tutor en su nombre dando el quenta con pago de la administraçion de los bienes que reçibiere", fol. XIX. 
Normalmente la intervención de los cónsules era puramente formal, aunque en ocasiones su mediación pudo ser decisiva, sobre todo en aquellas tutelas que debían cubrirse en situaciones especialmente difíciles 0 comprometidas. Así, por ejemplo, cuando tienen que sustituir a algún tutor que mantuviese conflictos de intereses con los menores ${ }^{38}$, o cuando por razones de edad, enfermedad, ocupaciones personales o profesionales fuese también excusable el ejercicio de la tutela ${ }^{39}$. Las ausencias de Brujas por motivos profesionales de los mercaderes castellanos fueron frecuentes, dando lugar a situaciones especialmente delicadas. Así el desamparo total de los ocho pequeños, hijos de Pedro de Porres, cuando pierden también a su madre y tutora Juana del Castillo, y contemplan que su único tutor vivo, Antonio de Guzmán, reside en Amberes, y no puede proporcionarles los cuidados y atenciones que todavia necesitan ${ }^{40}$.

\section{EJERCICIO Y OBLIGACIONES DE LA TUTELA}

Hemos visto, pues, que la autoridad consular sancionaba en su cargo a los tutores nombrados, a los que se podía exigir una fianza que, de algún modo, asegurase el cumplimiento de sus obligaciones. Pero ¿cúales eran realmente estas obligaciones? ${ }^{41}$. En general, velar por el tutelado, y en

38 Francisco de Béjar sustituirá a Juan de Matanza por el posible conflicto de intereses comerciales de éste con sus pupilos, hijos de Diego de Tordomar. Papeles sueltos. Cuadernillo de 2 hojas dobladas y cosidas, sin foliar.

39 El sistema de incapacidades y excusas para ser tutor fue perfectamente definido en las Partidas y lo recoge A. MERCHÁn Álvarez en su trabajo "La tutela...", ya citado, 142-160. Mención especial merece la prohibición de las segundas nupcias a la madre tutora, íbidem, 153-157.

40 Juan y Leonor de Porres, que son los dos hijos mayores de Pedro de Porres explican a los cónsules su situación de total desamparo tras el fallecimiento de su madre "no a abido persona que se aya encargado de la tutela de los dichos suplicantes ni de sus hermanos". Papeles sueltos. Hoja de papel doblada sin foliar. Poco después en un cuadernilio de dos hojas de papel doblado, sin foliar, se encuentra una carta de Antonio de Guzmán explicando a los cónsules de la Nación, su imposibilidad para abandonar Amberes y solicitando que le releven de su condición de tutor. "Muy magnificos señores, oy he recibido la carta de vuestras mercedes con la copia de la petiçion que dieron a vuestras mercedes los señores sus hijos del señor Pedro de Porres que aya gloria, veso las manos de vuestras mercedes por la merced que me han hecho en darme quenta destas cosas diversas que el señor Pedro de Porres me nombro por tutor de los señores sus hijos y despues de su muerte yo hize todo to que pude y lo que un vuen amigo pudiera hazer y quisiera yo mucho despues dela muerte dela señora Juana del Castillo allarme ay presente y desocupado para poder hazer lo mismo y encargarme de todo que vien lo hiziera porque lo debo a la grande amistad que tube con los padres de esos señores // pero yo me allo tan ocupado y avsente que doy mi fee a vuestras mercedes que no tengo lugar para poder salir un paso fuera desta villa ny podria yo encargarme dela tutela de esos señores porque seria darles muy mala quenta".

41 Con carácter general, las obligaciones del tutor, en A. MERCHÁn ÁlvAREZ, "La tutela...", 160, ciñéndonos aquí a las que aparecen reflejadas en el Libro de Tutorías. 
particular, procurarle alimentos, educarle y proporcionarle una formación adecuada: "e los rijan e gobiernen e dotrinen a su voluntad"..., "como buenos e leales tutores administraran las personas e bienes de los dichos menores"... ${ }^{42}$. También deben informar a la Nación sobre el estado del menor y rendirle cuenta anual ${ }^{43}$.

Todos estos deberes se iniciaban con la elaboración de un detallado y minucioso inventario de bienes del difunto "ynbentario e estado de todos los bienes y azienda allado en la casa mortuoria", paso previo y fundamental para conocer la hacienda real del fallecido de la que debían encargarse los nuevos administradores. La movilidad del mercader, la diversidad y complejidad de algunos de sus negocios, muchos de ellos inconclusos, podian entorpecer enormemente estas operaciones, convirtiendo esta primera función en una empresa laboriosa y difícil ${ }^{44}$. Fue frecuente que los tutores alegasen estos inconvenientes, la conveniencia de hacerlo con detenimiento, sin premuras, y solicitasen de las autoridades consulares una ampliación del plazo previsto para su elaboración ${ }^{45}$. Las dificultades propias de la heterogeneidad de los negocios podía incre-

42 En primer lugar, funciones que menciona Antonio de Villafranca cuando, en su testamento nombra a los tutores de sus tres hijos, fol. $X V$. $Y$ en segundo lugar, las que enumera Lope de la Corona, fol. XXVIII.

43 Son muchas de estas cuentas las que aparecen detalladas en el Libro de los menores, donde se comprueban estos gastos de manutención y formación. Por ejemplo, las de los hijos de Francico de Aranda, fol. VIII y las de los de Juan de Salinas, fol. XX.

44 La diversidad de bienes y negocios del mercader la refleja, por ejemplo, Josina Crampe, viuda de Fernando Matute cuando relata "yo he hecho el estado e ynventario de toda la asienda e bienes tanto muebles e raizes como rentas y cargazones y dinero de cambio y otras deudas que la dicha casa mortuoria fasta el dia de oy tiene", fol. 47. Continúa poco después justificando la tardanza por su preseritación ante las autoridades consulares "y la causa que antes de agora no e presentado a sido que al tienpo del falleçimiento del dicho mi marido la mayor parte dela azienda estaba en deudas por la tierra y en sacas en la lonja y en cargazones e deudas en Sevilla y en Castilla y en azeites comprados en Sevilla de por nabegar, que las mercaderias se vendieron a largos tienpos $y$ antes no se han podido tan presto recoger las deudas", fol. 47 . Son muchos los testimonios de este tipo que se insertan en el Libro de Tutorías, y que no incluímos por no alargar innecesariamente este trabajo.

${ }^{45}$ Todo el proceso descrito se refleja en la petición que los tutores de Juana de la Maza, hija de Francisco de la Maza, presentan ante los cónsules de la Nación: «piden y suplican los dichos pareçientes que por vs. magnificas mercedes les sea disçernida la dicha tutela, curadoria con las solenidades y poder en semejante caso acostunbrado y requerido y aunque es asi que debe ofreçer tanbien de su parte dellos un ynbentario y estado de todos los bienes y azienda allada en la casa mortuoria del dicho Francisco de la Maza todabia por la brebedad del tiempo no les a sido posible de tan presto azerlo por algunas quentas y mercaderias que no estan liquidadas por lo qual piden y suplican los dichos pareçientes pues que tanbien cunple a la pupila y a su probecho della como al descargo de los pareçientes que el dicho ynbentario se aga despacio y con grande recado y madura deliberaçion que plega a vs. magnificas ms. de les dar, conceder y otorgar el termino de un año para que dentro del azer y acabar el dicho ynbentario", fol. LII. 
mentarse si se añadian las provocadas por pleitos y litigios iniciados en vida del mercader difunto ${ }^{46}$.

Una vez concluído el inventario, se presenta ante los cónsules y se asienta en el Libro de Tutorías de la Nación con tal esmero, detalle y exactitud ${ }^{47}$ que nos recuerda a algunos de sus otros libros de cuentas. Observamos, entonces, un gran interés por reflejar que se han respetado las leyes hispanas ${ }^{48}$ y por anotarlo todo, por no olvidar ni el mas mínimo ni nimio detalle, señalando las diferentes partes que corresponden a cada uno de los herederos, y descontando también a cada uno de ellos los gastos que, proporcionales a su parte de la herencia, les correspondía sufragar. En principio a los menores se les descuenta todo tipo de gastos: enterramiento, exequias, los derivados de la elaboración del propio inventario... sin ninguna compasión o rasgo de generosidad por parte del cónyuge superviviente. Una de las pocas excepciones con que nos encontramos es la de Catalina Van Viven, viuda de Luis Gallo, quien renuncia a todos sus posibles derechos en las personas de sus hijos Luis y Ana ${ }^{49}$.

46 Seria el caso de Luis Gallo, quien mantenía pleitos en España con su madre y hermanos. Su viuda, Catalina Van Billen, alude al retraso que ello impone en la elaboración del estado de cuentas (fol. 34). Francisca de Castro, viuda de Luis de la Vega, solicita también el plazo de un año para la presentación del inventario aludiendo a los negocios de su esposo difunto "por quanto en la casa mortuoria del dicho mi marido que aya gloria, quedaron y ay en ser algunas sacas de lana y otras mercaderias y de España se esperan otras algunas mas que estan hechas y cargadas para estos estados y bendiendose estas sacas a draperos o a españoles fiadas por algun tienpo tenian mas valor $y$ preçio que no vendiendose a pagar al contado, pido y suplico a vs. ms. me autoricen y den tacultad para que las dichas sacas que ay en ser y las que mas venieren las pueda vender fiadas o de contado de la manera que mejor pudiere y me paresçiere ser mas en benefiçio mio y de mis hijos, para que vendidas se pueda poner el valor dellas en el estado e ynbentario general de la hazienda". Con anterioridad habia señalado "por quanto la hazienda desta casa mortuoria esta repartida y derramada en diferentes partes y lugares tanto en estos estados como en España, Ytalia, Françia y en otras partes". Y poco después su hijo explicaria la imposibilidad de hacer el inventario en el plazo de seis meses, fol. 80 .

47 Ver, por ejemplo, el estado de la casa mortuoria de Juan de Camargo (fol. XLV), el inventario del Dr. Valdaura (fol. XXVII), de Gonzalo de Salamanca (fol. XX|X), de Diego de Astudillo (fol. $X X X$ ), de Juan de Medina (fol. 34), de Luis Gallo (fol. 34 y 35 y XXXVI. XXXVII, donde se recogen también las rentas posteriores de esta hacienda). Ver también el inventario de Juana de la Torre (fol. XXXVIII), de Fernando de Matute (fol. 47 y 48), de Antonio de Nájera (fol. LI y L.II), de Silvestre Pardo (fol. LIIIl y 57), de Francisco de la Maza (fol. 58 y 59), de Garcia de Castro (fol. 62 y 65), de Pedro de Valencia (fol. LXXIII), de Angela de Granada (fol. LXXVI), y de Francisco de la Torre en papeles sueltos.

${ }_{48}$ Este interés es mayor si la viuda es flamenca. Así Josina Crampe relatará que se observaron «las leyes, fueros e derechos e constituçiones del reino de España e supuestos desta naçion donde yo me e tenido e tengo". Lo mismo haria Catalina Van Viven, viuda de Luis Gallo, fol. 34 .

49 Remitimos a las cuentas mencionadas en la nota 42 . En cuanto a la renuncia de Catalina Van Viven, ella declarará ante los cónsules que sabe que los frutos de los bienes de sus hijos menores pertenecen a éstos y no a ella, y que renunciaba a cualquier posible derecho sobre los 
Aclaradas las cuentas, conocidos los bienes disponibles, los tutores comienzan a actuar guíados por un único principio, casi una obsesión: mantener el patrimonio, que la hacienda no disminuya. Poco o nada importa que no se incremente, lo realmente fundamental y decisivo es que no decrezca.

"Y que los bienes de los dichos menores syenpre esten en pie syn benyr en dismynizion e menoscabo de lo que agora son " ${ }^{50} . .$.

$Y$ así, orientan todas sus acciones hacia las inversiones consideradas más seguras, hacia la compra de algunas propiedades inmobiliarias ${ }^{51}$, pero sobre todo hacia los títulos de renta con un interés fijo establecido de antemano y que oscilaba entre el 6 y el $8,5 \%{ }^{52}$, y del que se espera puedan mantenerse los menores. Siempre habían de buscar la mayor seguridad para el menor "como buen tutor debe haçer" 53 , aunque el difunto en su testamento les hubiese conferido total libertad de movimiento. Es el caso de Antonio de Villatranca con respecto a Alonso de Santa Gadea,

mismos: "dixo que ella estaba ynformada de que el dicho usofruto perteneçia a los dichos meno. res y no a ella segun la costumbre e derecho de los supuestos desta naçion, pero a mayor abundançia dixo que si algun derecho o action tiene a los dichos usofrutos o lo puede tener lo renunçiaba en los menores, sus hijos, e les hazia donaçion yrebocable entre bivos del derecho que podria en alguna manera pretender y renunçiaba qualquier derecho que en su fabor poderia ser", fol. XXXVII.

50 Fol. XIIII.

51 Los tutores de los hijos de Antonio de Villafranca exponen: «nos parece ser cosa conveniente y provechosa a los dichos menores emplearles la hazienda que el dicho defunto dejo a los dichos hijos en posesiones y rentas no obstante que podriamos tenerlo de contado como bien visto nos fuese a risgo de los dichos menores nos paresçio de presente que una caseria que era de la dicha s. $^{a}$ viuda y sus hermanos situada junto a Estrenburgo cerca desta villa de Brujas la quieren vender y nos pareçe ser cosa conveniente y que es para la seguridad de los dichos menores e provecho es bien tomarla para ellos asi que suplicamos a vs. ms. como a superiores tutores de dichos menores nos manden dar licencia y de su ofiçio nos autorizen para lo poder hazer y en lo asi hazer haran vs. ms. serviçio a Dios y provecho a los menores", fol. XXVIII.

52 En ocasiones se venden propiedades inmobiliarias para adquirir títulos de renta. Así lo propone Diego de Santo Domingo como tutor de los hijos de Francisco de Aranda "por que le paresçia ser mas conbeniente e util a los dichos menores se bendiese la dicha casa para que lo que della se toviese se podiese enplear en renta o en otra cosa mas provechosa a los dichos menores", fol. IIII. Al $7 \%$ lo concierta Diego de Santo Domingo como tutor de los hijos de Francisco de Aranda, fol. IIII. Poco después concertaron otra cantidad al $8,5 \%$ anual para un período de cuatro años, fol. IX. Un $7 \%$ es el interés que reciben los hijos de Juan de Salinas, fol. XX; $6 \%$ "con mas el ynterese e ynterese de yntereses a razon de seis por çiento al año por el tienpo que lo tubiere desde oy dia de la fecha en adelante"..., fol. XXI. El $61 / 4$ por un periodo de tres años, recibirán los hijos de Diego de Avila «a rason de seis y un quarto por çiento cada un año y pagare dicho usufructo de medio en medio año para alimentos de los dichos menores a la dicha Madalena de Mill por todo el tienpo de los dichos tres años", fol. XXV; 7 3/4 para un período de dos años "a siete e tres quartos por çiento en cada uno delos dichos años con el ynterese del ynterese", fol. XXIX.

53 Expresiones de este tipo "quel procuraria de aprovechar los dichos menores e a sus bienes como a sus cosas propias e como buen tutor deve haçer", fol. III, resultan habituales. 
Juan de Camargo y Juan del Castillo, tutores de sus cuatro hijos ${ }^{54}$, y de Juan de la Peña ${ }^{55}$.

Su lema podría ser conservar, no incrementar. Las inversiones preferidas veíamos que eran aquellas que ofrecían una mayor seguridad: propiedades inmobiliarias o rentas con un interés previamente fijado. Ningún tutor se permitiría la osadía de invertir en operaciones comerciales. Pero si a alguno, especialmente arriesgado o emprendedor, se le ocurriese, los cónsules, en su calidad de tutores supremos, no estarían dispuestos a consentirlo. Así vemos cómo paralizan y frenan las iniciativas de los tutores de los hijos de Pedro de Valencia e Isabel de Quintanadueñas a pesar de que éstos alegan insistentemente la voluntad del difunto -recogida en su testamento- para hacerlo ${ }^{56}$. Isabel de Quintanadueñas, viuda del difunto, y Cristóbal Pesquer, yerno y socio del mismo, ambos tutores designados en testamento se esfuerzan por demostrar que el deseo del fallecido siempre había sido la inversión en mercaderías, el trato comercial, y presentarán diferentes testigos que así lo avalen. A pesar de esta insistencia ${ }^{57}$, los cón-

54 "Pido e requiero desde agora a la justiçia ante quien parecyeren les disierna la dicha tutela sin pedirles fianza de la administracion de los dichos mis hijos ni de sus bienes, porque es mi boluntad de relebarlos como los reliebo de la dicha fiança e quiero y es mi boluntad que puedan husar de los bienes de los dichos mis hijos en todo el tienpo dela dicha tutela a su boluntad asi tratandolos de mercaderias como enpleandolos en renta como teniendolos en ser de forma que les doy libre albedrio para que hagan dellos lo que mejor les pareziere", fol. XV.

55 "Traten y administren como quisieren e bien visto les fueren en qualquier trato o negoçio que bien les paresçiere", fol. 60 .

${ }_{56}$ "Que su yntençion y boluntad fue que la hazienda de sus hijos e hijas fuese despues de sus dias tratada y negoçiada en comerçios y tratos de mercaderes como Dios diere a perdida y ganançia", Papeles sueltos. Cuadernillo de cinco hojas de papel dobladas, cosidas, sin foliar. La petición ya se había presentado con anterioridad, cuando los tutores presentan relación de bienes del difunto ante la autoridad consular, fol. LXXII.

57 "Que despues de sus dias la azienda de sus hijos e menores que se tratase en trato de mercader como el lo tratava y no en renta". Así respondia Francisco de San Vítores, residente en Amberes, a la pregunta siguiente presentada por los tutores, "que digan sy saben o an oydo desir al dicho Pedro de Valençia, defunto, antes de su falleçimiento que hera su voluntad que despues de el falleçido, los bienes que a sus hijos e hijas avidos en la señora Ysabel de Quintanadueñas les perteneçiesen, que los tratasen e benefiçiasen en el trato de mercaderia la dicha señora biuda y Juan de Peralta e Cristobal Pesquer». A esta cuestión, la propia Isabel de Quintanadueñas responde "que ella, en persona, oyo dezir al señor Pedro de Valencia, defunto, su marido, muchas vezes y espeçialmente la ultima vez çinco o seys dias antes que muriese que su voluntad hera que despues de su falleçimiento se tratasen los bienes e azienda que del quedasen de sus hijos e hijas menores avidos en la dicha señora declarante en mercaderias como el avia tratado, parte en España, parte en estas tierras como a sus cabecaleros les pareçiese". Cristóbal Pesquer, recién llegado de la Peninsula declarará que el difunto "dixo a este declarante que el dinero que el defunto tenia en su compañya del dicho Pesquer si queria el dicho Pesquer que se tratase delay adelante como asta entonces". Juan de Peralta comparte esta opinión "hera la volunad del defunto que los bienes de los dichos menores despues de su falleçimiento se tratasen a perdida e ganançia en trato de mercaderes". Papeles sueltos. Cuadernillo de cinco hojas de papel dobladas, cosidas, sin foliar. 
sules nunca lo aceptaron ${ }^{58}$, dando muestra estas decisiones consulares de un conservadurismo a ultranza. Por tanto, aquellos descendientes de mercaderes, huérfanos, muy especialmente interesados en este tipo de inversiones, tuvieron que esperar a su mayoría de edad, a liberarse de la tutela consular, para poder hacerlo. $Y$ para entonces, quizá, su hacienda estuviese muy mermada. Precisamente Pedro de Valencia, hijo legítimo del mencionado Pedro de Valencia, así tuvo que hacerlo, y al acercarse a los 23 años solicitó la parte de la hacienda que le correspondía, porque "deseaba hazer provecho y ayudarse de sus bienes en el trato y estilo mercantil» 59 .

\section{EXTINCIÓN DE LA TUTELA. PROVISIÓN DE CURADORES}

La tutela se extingue con la mayoria de edad "edad competente» -12 años para las mujeres, 14 para los varones- ${ }^{60}$, iniciándose una nueva etapa, la curaduría, claramente diferenciada de la anterior. Porque la tutela se refería a la persona del menor, aunque también podía afectar a la administración de sus bienes, y la curaduría es una tutela restringida que afecta exclusivamente a esta administración del patrimonio. Los curadores pudieron ser nombrados también en el testamento del fallecido o bien nombrarse con posterioridad. En este caso, eran los propios menores los que se presentaban ante las autoridades consulares solicitando un curador o persona para cuidar sus bienes y negocios. En esta circunstancia casi siempre el cargo recaía sobre la madre de los solicitantes ${ }^{61}$, o sobre al-

\footnotetext{
58 "Declaramos que no allamos causa ni ynformaçion bastante para conceder a los remostrantes la sobre dicha liçençia e autorizaçion por ellos pedida"..., Papeles sueltos.

59 Ante los cónsules de la Nación, el citado Pedro de Valencia demostró "que el hera llegado a hedad de veynte $y$ tres años açercandose su hedad competente y por quanto el deseaba hazer provecho $y$ ayudarse de sus bienes en el trato y estilo mercantil», fol. LXXIIII.

60 "Antes que los dichos mis hijo e hijas lleguen a edad competente que es de doze años las mugeres e de catorze los barones", fol. XV

61 Isabel de Villafranca, hija legitima de Antonio de Villafranca y de Godeliva Van de Beide, solicita ante las autoridades consulares que ésta, su madre, sea nombrada su curadora "porque el tienpo de la tutela es ya espirado por ser yo mayor de doze años y menor de veinte e dos, por donde conbiene yo sea probeida de curador, pido a vs. ms. en la mejor forma que puedo me probean de curador para que reciba mis bienes", fol. XL. Unos años después, también lo harian sus hermanos Antonio, Catalina y María de 17,18 y 16 años respectivamente, fol. LIII v. Adrián de Villegas y Margarita de Villegas, hijos de Francisco Fernández de Villegas y de Adriana de Bot, solicitaron asimismo que fuese ésta su curadora "por quanto yo, el dicho Adrian de Villegas soi mayor de catorze años e yo la dicha Doña Margarita de Villegas soi mayor de doze años, por cuya causa la tutela de que el señor nuestro padre nos dexo encargados es espirada, por lo qual pedimos ser probeidos de curadores que tomen cuenta de nuestras haciendas". "Y para ello nombramos a la dicha señora Doña Adriana de Bot, nuestra madre».
} 
gunos de sus hermanos mayores o cuñados ${ }^{62}$. Volvemos a encontrarnos con la exigencia de viudedad, sobre todo si el nombramiento de tutor y curador había sido simultáneo ${ }^{63}$.

Los curadores atenderían los negocios hasta que se alcanzasen los 25 años o se contrajese matrimonio o se "tomare estado" "64, cuando definitivamente los pupilos concluyesen su larga espera.

Al cesar en sus funciones, tutores y curadores debian rendir cuentas generales de su administración ante la autoridad consular, aunque en algunas ocasiones hay mención expresa, deseo del difunto, para que se exima a los por él nombrados de esta obligación, o que por lo menos presenten las cuentas que ellos mismos estimen oportunas ${ }^{65}$. Dulcificaban de

62 Francisco y Alonso Páez, eran los curadores de sus hermanos pequeños Margarita, Diego y Gregorio, fol. XXX|X, y Francisco y Diego de Aranda de su hermano Alexandre, fol.46, Diego de Lerma de su cuñado Juan de Camargo, que será quien lo solicita presentándose ante las autoridades consulares: "como ha mucho que el paso los catorze años en que se acaba y expira la tutela tanto de segun las leys y pregmaticas del reyno de Castilla como segun a dispusition del derecho comun siguiendo a esto que pues el esta determinado de proseguir sus estudios por si en començados, a saber, la profesion de las leyes, que manden vs. ms. dar y disçernir por curador de su hazienda a su cuñado el señor Diego de Lernia como mas çercano pariente teniendo en su merçed entera confiança que cunplira su cargo debidamente".

63 Juan de la Peña nombra como ya habiamos visto tutora y curadora de su hijo Juan a su esposa María Yánez. Fijémonos en sus disposiciones sobre la curaduría: "e pasado el tiempo de la tutela del dicho Juan de la Peña, nuestro hijo, quiero e mando y es mi boluntad que asta que llegue su tiempo de hedad de beinte $y$ çinco años o tomare estado, que la dicha señora su madre sola sea su curadora de sus bienes y los trate y benefiçie y negoçie como a ella le pareçiere e bien visto le fuere, "bien entendido que si la dicha mi querida muger se casare la aparto y desapodero desta tutela e curaduria e nombro solo al señor mi hermano Garcia de la Peña por tutor e curador del dicho mi hijo". Lo mismo dispondrá Diego Pardo: "ytem nombro y declaro por tutores $y$ curadores de personas y bienes de mis herederos naçidos e por naçer a la señora Doña Ysabel de Villegas, mi esposa y muger, y al dicho señor Juan Lopez Gallo, señor de Mala y Çiçela, pero entiendese y declaro que si la dicha muger se tornase a casar que no quiero que sea tutora ni curadora y tambien declaro por tutor y curador al dicho señor Antonio de Bega si se casare con la sobredicha mi hija Josina y si no se casare no", fol. LXXI.

64 Estos supuestos recogidos en la nota precedente, también se comprueban en la solicitud de Luis de Camargo "segund el derecho y las costumbres y leis de España la curaduria espira, feneçe y acaba despues de los beinte y cinco cumplidos los quales el suplicante tiene muy cunplidos e acabados", fol. XLI.

65 Antonio de Villafranca nombró como tutores de sus hijos a Alonso de Santa Gadea, Juan de Camargo y Juan del Castillo, a los que concedió, tal y como vimos, gran libertad en la disponibilidad de sus bienes subrayando que "en el fin de la dicha tutela mando y es mi boluntad que no sea pedida a los dichos tutores por los dichos mis hijos e hijas ni por otro en su nombre otra cuenta alguna de los frutos de los dichos bienes mas de la que ellos quisieren dar, la qual dende agora apruebo yo por buena", fol. XV. Juan de la Peña también da por buenas esas futuras cuentas: "que no pueda demandar quenta ni razon alguna a los dichos sus tutores ni curadora mas de aquella que ellos dieren, dixeren e declararen por sus simples juramentos", fol. 60 . Al igual que Pedro de Porres quien también insistirá: "los dichos mis hijos y hijas ny ninguno dellos ny otro por ellos no puedan pedir ny pidan ninguna otra quenta ny razon de los dichos bienes a los dichos sus 
este modo las obligaciones de los tutores, siempre incómodas y difíciles como hemos visto. Algo que había que hacer, que se entendía como una obligación moral, un deber cristiano y un favor a un amigo, cuando éste, lejos de su tierra, lo necesitaba mas que nunca ${ }^{66}$.

Obligación gravosa para los tutores, larga y difícil espera para los menores porque, si en general la infancia en la Edad Media se ha contemplado como un período sin entidad propia, como una etapa de espera hacia el mundo de los adultos, particularmente penoso resulta este compás de espera en el caso de las minorías de edad que aquí abordamos. Se desea que se hagan cargo lo antes posible de sus bienes, y mientras llega ese momento, un interés obsesivo: que el patrimonio heredado no disminuya y, a la vez, permita satisfacer las necesidades de los tutelados hasta que crezcan.

Contemplamos los periodos de minoría de edad como especialmente delicados en la historia de las familias de mercaderes, pues podemos decir que suponían el principio del fin, al menos en lo que se refiere a su vinculación con el mundo de los negocios. Y no sólo porque los niños pudiesen ser objeto de las ambiciones de sus parientes sino, sobre todo, porque la obsesión por conservar sus bienes suponía no incrementarlos. Y la ya disgregada hacienda paterna, que había sufrido diversas particiones, no podía soportar ni resistir la inactividad de la inversión durante una larga espera. Si para los huérfanos de los mercaderes castellanos en Brujas, la vinculación con el mundo del gran comercio desde puestos de especial protagonismo había acabado, acaso también su vida acomodada.

curadores e tutores mas de la que quisieren dar". Papeles sueltos. Cuadernillo de una hoja de papel doblada sin foliar.

También A. MERCHÁN ÁlVAREZ dedica todo un capítulo del trabajo tantas veces mencionado al control sobre el ejercicio de la tutoría, pp. 191-205, y a la protección atenuada o curatela, pp. 209-231.

${ }_{66}$ Juan de Camargo en la claúsula testamentaria en la que nombra tutores pide a éstos que acepten "les suplico por amor de Dios se encarguen deste cargo por quanto hyziere yo lo mismo sy ellos o cada uno dellos me lo rogara", fol.XL. Antonio de Guzmán, tutor de los hijos de Pedro de Porres, cuando por residir en Amberes no puede hacerse cargo de la tutela encomendada, agravada entonces por el fallecimiento de la madre de los pequeños, alude también a la obligación moral de hacerlo, "el señor Pedro Porres me nombro por tutor de los señores sus hijos y despues de su muerte yo hize todo to que pude y lo que un vuen amigo pudiera hazer y quisiera yo mucho despues de la muerte de la señora juana del Castillo allarme ay presente y desocupado para hazer lo mismo y encargarme de todo que bien lo hiziera porque lo debo a la grande amistad que tube con los padres de los señores"... Papeles sueltos. Cuadernillo de dos hojas de papel dobladas y sin foliar. 